\title{
Prevalence of depression and factors associated with Brazilian workers
}

\begin{abstract}
Objective: To describe the prevalence and analyze the factors associated with depression related to workers in Brazil.

Methods: cross-sectional analysis, which used data from the National Health Survey, which took place in 2013. The variables analyzed were gender, age, skin color, education, smoking, sleep deprivation, country region and occupation. Descriptive measures were taken as prevalence of the injury and association with odds ratio.
\end{abstract}

Results: the prevalence of aggression was $6.2 \%$ among workers and the categories most related to women, aged from 40 years, higher education level, smokers, southern region of the country and occupations of health, trade and repair and basic sanitation.

Conclusion: of the categories associated with the outcome of some confirmed literature, and others in particular, such as branches of economic activities, use of new studies for better elucidation as a factor associated with depression in workers.

Keywords: prevalence, depression, epidemiology, occupational health, population
Volume 3 Issue $6-2019$

\author{
Rafael Haeffner,' Leni de Lima Santana ${ }^{2}$ \\ 'Program in Epidemiology, University of Sao Paulo, Brazil \\ ${ }^{2}$ Program in Nursing, University of Parana, Brazil
}

Correspondence: Rafael Haeffner, Street Padre João Wislinski, number II 9, neighborhood Santa Cândida, Postal Code: 85003 160, Curitiba, PR, Brazil, Tel 55041985004766,

Email rafaelhaeffne@gmail.com

Received: December 09, 2019 | Published: December 27, 2019
Abbreviations: NHS, national health survey; MH, ministry of health; PPH, permanent private homes; PDAs, personal digital assistance; NCEA, national classification of economic activities; OR, odds ratio; IBGE, Brazilian institute of geography and statistics

\section{Introduction}

The social and labor demands inherent in human development have, to some extent, always contributed to the physical and emotional strain of the population in general. Transformations in the socioeconomic model have contributed to increased competitiveness, which requires greater productive capacity and thus increasing the risk of illness, especially in the occupational field. ${ }^{1}$ Several studies have concentrated efforts to understand the influence of work on workers' illness, both regarding physical and mental illnesses. ${ }^{1-7}$ From a psychological point of view, depression, along with anxiety and stress, has been highlighted among work-related mental disorders. This is due to the increased number of cases and the resulting impacts on both the sick individual and the employer as well as and society as a whole.The depression is currently estimated to affect about 322 million people worldwide, being the leading cause of disability on the planet, with serious impacts on the world of work, as much of the prevalence is concentrated in the productive population Brazil is the Latin American country with the highest prevalence of cases in the general population, around 11.5 million Brazilians. ${ }^{3,8}$

The depression is considered a chronic disease with high recurrence rates. It is estimated that approximately $60 \%$ of people who have an episode of depression have the symptoms repeated at least once in their lifetime. The data is clinically relevant since recidivism interferes with the health and quality of life of the patient, contributes to social isolation, affects their productive capacity and impairs their maintenance in the labor market. ${ }^{1,2}$ In addition, symptoms related to cognitive problems such as difficulty concentrating, distractions, memory loss, and difficulty performing daily tasks, ${ }^{1}$ as well as psychosomatic, neurological symptoms, feeling of sadness, mood loss, thoughts, and suicide attempts contribute to for low productivity and premature death in people with depression. ${ }^{8}$ This is due to the association with other health problems and, in more severe cases, to death by suicide, increasing the economic impact of this disease. ${ }^{9}$

The etiology of depression is considered multicausal and involves both physiological and psychological factors. ${ }^{5}$ However, studies show that, when it comes to worker health, occupation and organizational factors may influence its occurrence or aggravate its symptoms when pre-existing disease..$^{2,10}$ However, it is noteworthy that, regardless of the causes or risk factors, depression is a treatable and often preventable disorder. ${ }^{1,9}$ Thus, disease prevention and health promotion actions should be priorities both globally and in the workplace. However, health promotion and disease prevention actions should always be guided by indicators that express reality and direct actions.In front of the exposed and considering that Brazil currently has approximately 105 million economically active people ${ }^{11}$ it is necessary to study with a comprehensive and representative sample plan of the population residing in the country to analyze the event of depression in workers. Thus, the objectives of this study are to describe the prevalence and to analyze the demographic and occupational social factors associated with self-reported depression in Brazilian workers in 2013.

\section{Methods}

This is an epidemiological cross-sectional population-based study conducted in Brazil in 2013, the prevalence of which was a lifetime analysis. The micro data were used from the National Health Survey (NHS) conducted by IBGE in partnership with the Ministry of Health (MH). ${ }^{12}$ The research participants were residents of permanent private 
households, living in both urban and rural areas, whose coverage area was the entire territory of Brazil.

The PNS data were obtained from a complex sampling plan, with multiple selection clusters, as follows: 1st stage (UPA) - census tract or set of census tracts (with at least 60 Permanent Private Homes$\mathrm{PPH}$ ), with probability of selection proportional to the number of PPH; 2nd stage - selection by simple random sampling of households in each UPA; 3rd stage - simple random sample selection of a resident 18 years of age or older per household. ${ }^{12}$ Data collection through interviews was performed by properly trained interviewers, with the help of PDAs (Personal Digital Assistance), handheld computers, properly programmed for the critical processes of variables. ${ }^{12}$ The dependent variable was assessed by applying the following research question: "Has any physician or mental health professional (such as a psychiatrist or psychologist) already diagnosed you with depression?" (Yes/no). ${ }^{12}$

For this study, the independent variables selected were sociodemographic, lifestyle and occupational variables: gender (male, female); age group ( $\leq 29$ years, 30 - 39 years, 40 - 49 years, 50 - 59 years, $\geq 60$ years); skin color (white and non-white); educational level (uneducated, elementary school, high school, and higher education), smoking (yes/no), sleep deprivation (yes/no). Residence that was categorized by region of the country (north, northeast, southeast, south and midwest).The classes of the National Classification of Economic Activities (NCEA) were divided into 12 categories: agriculture; transformation industry; sanitation and the like; construction; trade and repair; transport and storage; accommodation, food and communication; administrative services (financial, administrative, real estate, professional, scientific and technical activities); education, arts, culture and sport; domestic services; others (mining, electricity, gas, and international organizations).Regarding the data analysis, it was initially descriptive with the population projection of the sample based on the necessary weights. Absolute and relative frequencies of categorical variables were made, in addition to the $95 \%$ confidence interval. For age, the mean and interquartile range were calculated.

As this is a "rare" prevalence event in this study, for the univariate analysis, the Odds Ratio (OR) with the Logistic Regression was performed to obtain the effect measure for association with $95 \% \mathrm{CI}$ between the dependent variable (self-reported depression) and the independent variables (gender, age, skin color, level of education, region of the country, smoking, insomnia and NCEA), considering significant $\mathrm{p}<0.05$.After univariate analysis between the dependent variable and the independent variables, the adjusted analysis with the Logistic Regression was performed. The multiple analysis was of stepwise forward type, being included in the multiple model the variables with $\mathrm{p}<0.2$ by the maximum likelihood method in the univariate analysis, considering significant $p<0.05$. It was found that the final logistic model obtained the appropriate fit $(p>0.05)$ by Archer and Lemeshow's goodness-of-fit test.The analyzes were performed in the survey module of Stata software version 12.1 (StataCorp., CollegeStation, United States), taking into account the research weights. Records of non-economically active persons under 18 years of age were excluded. The final sample after the exclusions were 36.187 people. This study did not require approval by the ethics committee as it were conducted from a public domain secondary data source (PNS), available online from the Brazilian Institute of Geography and Statistics (IBGE). There was no identification of the research participants, ensuring anonymity.

\section{Results}

In 2013, the projection of workers in Brazil was 89.481.382. The mean age was 38.8 years and the interquartile age range was 18 to 90 years. The predominant categories were male, with $57.1 \%(95 \%$ CI: $56.2 ; 58.1)$; less than or equal to 29 years, with $27.9 \%$ (95\% CI: 26.5; 28.1); non-white, with 51.8\% (95\% CI: 50.1; 52.8); high school, with $37.8 \%$ (95\% CI: 36.9; 38.8); non-smokers, with $84.7 \%$ (95\% CI: 84.0 ; 85.3); from the southeast region, with $43.9 \%$ (95\% CI: 42.9 ; 44.8) (Table 1).With regard to depression, the prevalence was $6.2 \%$ (95\% CI: $5.8 ; 6.7)$ in the working population, and the groups with the highest proportions were female workers $(10.2 \%)$; age from 40 to 49 years $(8.2 \%)$ and 50 to 59 years $(8.2 \%)$; whites $(7.4 \%)$; with higher education $(7.5 \%)$; smokers $(8.1 \%)$; from the southern region of the country $(10 \%)$ (Table 2$)$. The average age of workers with depression was 42.3 years.In the univariate analysis, the categories most associated with the outcome were females, with an OR of 3.11 (95\% CI: 2.63 ; 3.66); age group from 40 to 49 years old, with OR of $2.38(95 \%$ CI: $1.87 ; 3.03)$ and from 50 to 59 years old, with OR of 2.38 (95\% CI: $1.83 ; 3.05)$. Also in relation to age, an OR of 1.02 per year of increase was observed ( $95 \%$ CI: $1.01 ; 1.03 ; p<0.001)$. There was also a greater association among white workers, with OR of 1.43 (95\% CI: $1.24 ; 1.64)$; higher education, OR of 1.68 (95\% CI: 1.24 ; $2.21)$; smokers, OR of 1.37 (95\% CI: $1.15 ; 1.63)$; from the south of the country, OR of 4.00 (95\% CI: 3.22; 4.98) (Table 3)and (Table 4).The variables that maintained an independent effect on the multiple analysis were gender, age, education, smoking, region and ANC. During the modeling process, the variables that best fit the final model were the region of the country that exerted adjustment especially on skin color and education. Gender adjusted for NCEA and education, and insomnia mainly adjusted for gender and age.

Table I Characteristics of workers according to the variables gender, age, skin color, educational level, smoking and region of the country. Brazil, 2013

\begin{tabular}{|c|c|c|c|}
\hline Variable & Population & \% (Cl95\%) & $\begin{array}{l}\text { Depression \% } \\
\text { (Cl95\%) }\end{array}$ \\
\hline \multicolumn{4}{|l|}{ Sex } \\
\hline Male & 51.132 .079 & $57, I(56,2 ; 58, I)$ & $3,3(2,8 ; 3,8)$ \\
\hline Female & 38.349 .303 & $42,9(41,9 ; 43,8)$ & $10,2(9,4 ; 1 \mid, 0)$ \\
\hline \multicolumn{4}{|l|}{ Age range } \\
\hline$\leq 29$ years & 24.943 .750 & $27,9(27,0 ; 28,7)$ & $3,4(2,8 ; 4,2)$ \\
\hline $30-39$ years & 24.423 .270 & $27,3(26,5 ; 28, I)$ & $6,0(5,3 ; 6,8)$ \\
\hline 40-49years & 19.651 .156 & $22,0(21,2 ; 22,7)$ & $8,2(7,2 ; 9,4)$ \\
\hline 50-59years & $14.517 .10 \mid$ & $16,2(15,5 ; 16,9)$ & $8,2(7,0 ; 9,6)$ \\
\hline$\geq 60$ years & 5.946 .104 & $6,6(6,2 ; 7,1)$ & $7,4(5,7 ; 6,7)$ \\
\hline \multicolumn{4}{|l|}{ Skin color } \\
\hline No white & 46.314 .320 & $5 \mathrm{I}, 8(50,1 ; 52,8)$ & $5,2(4,7 ; 5,7)$ \\
\hline White & 43.167 .062 & $48,2(47,2 ; 49,2)$ & $7,4(6,7 ; 8, I)$ \\
\hline
\end{tabular}


Table Continues...

\begin{tabular}{|c|c|c|c|}
\hline Variable & Population & \% (CI95\%) & $\begin{array}{l}\text { Depression \% } \\
\text { (Cl95\%) }\end{array}$ \\
\hline \multicolumn{4}{|c|}{ Educational level } \\
\hline Unread & 7.797.85I & $8,7(8,2 ; 9,2)$ & $4,5(3,5 ; 5,6)$ \\
\hline $\begin{array}{l}\text { Elementary } \\
\text { school }\end{array}$ & 28.326 .186 & $31,7(30,7 ; 32,7)$ & $7, I(6,3 ; 8,0)$ \\
\hline High school & 33.870 .502 & $37,8(36,9 ; 38,8)$ & $5,2(4,5 ; 5,9)$ \\
\hline $\begin{array}{l}\text { Higher } \\
\text { education }\end{array}$ & 19.486 .842 & $21,8(20,7 ; 22,8)$ & $7,5(6,5 ; 8,7)$ \\
\hline \multicolumn{4}{|l|}{ Smoking } \\
\hline No & 75.784 .552 & $84,7(84,0 ; 85,3)$ & $5,9(5,4 ; 6,4)$ \\
\hline Yes & |3.696.830 & $15,3(14,7 ; 16,0)$ & $8, I(6,9 ; 9,5)$ \\
\hline \multicolumn{4}{|l|}{ Region } \\
\hline North & 6.505 .346 & $7,3(6,9 ; 7,5)$ & $2,5(2,1 ; 3,0)$ \\
\hline Northeast & 22.213 .654 & $24,8(24, I ; 25,6)$ & $4, I(3,6 ; 4,7)$ \\
\hline Southeast & 39.261 .297 & $43,9(42,9 ; 44,8)$ & $6,7(5,9 ; 7,6)$ \\
\hline South & $|4.43| .967$ & $16,1(15,5 ; 16,7)$ & I0,0 (8,8; II,4) \\
\hline Midwest & 7.069 .118 & $7,9(7,6 ; 8,2)$ & $6,2(5,3 ; 7,2)$ \\
\hline
\end{tabular}

(C195\%): confidence interval of $95 \%$

Table 2 Characteristics of workers according to the variables sleep deprivation and National Classification of Economic Activities. Brazil, 2013

\begin{tabular}{|c|c|c|c|}
\hline Variable & Population & $\%(\mathrm{Cl} 195 \%)$ & $\begin{array}{l}\text { Depression } \\
\text { (CI95\%) }\end{array}$ \\
\hline \multicolumn{4}{|l|}{ Sleep deprivation } \\
\hline No & 66.136 .981 & $73,9(73,0 ; 74,8)$ & $3,7(3,3 ; 4,2)$ \\
\hline Yes & 23.344 .401 & $26, I(25,2 ; 26,9)$ & $13,3(12,2 ; 14,6)$ \\
\hline \multicolumn{4}{|l|}{ NCEA } \\
\hline Transport and storage & 3.998 .018 & $4,5(4, I ; 4,9)$ & $2,3(1,6 ; 3,8)$ \\
\hline $\begin{array}{l}\text { Agriculture, fishing and } \\
\text { livestock }\end{array}$ & 9.796 .299 & $10,9(10,3 ; 11,6)$ & $4,9(3,8 ; 6,4)$ \\
\hline Transformation industry & 10.841 .493 & $12,1(1|, 4 ;| 2,8)$ & $5,9(4,8 ; 7,2)$ \\
\hline Sanitation & 773.887 & $0,9(0,7 ; 1,1)$ & $7,8(3,3 ; 17,4)$ \\
\hline Construction & 7.777 .603 & $8,7(8,1 ; 9,3)$ & $3,9(2,6 ; 5,7)$ \\
\hline Trade and repair & 17.798 .200 & $19,9(19,1 ; 20,7)$ & $5,7(4,8 ; 6,8)$ \\
\hline $\begin{array}{l}\text { Accommodation, food and } \\
\text { communication }\end{array}$ & 5.195 .833 & $5,8(5,4 ; 6,2)$ & $6,1(4,7 ; 7,9)$ \\
\hline Administrative services & 14.266 .974 & $15,9(15,2 ; 16,6)$ & $6,2(5,2 ; 7,3)$ \\
\hline $\begin{array}{l}\text { Education, arts, culture and } \\
\text { sport }\end{array}$ & 6.652 .276 & $7,4(6,9 ; 7,9)$ & $9,6(7,6 ; 12,0)$ \\
\hline Health and social services & $5.744 .61 \mathrm{I}$ & $6,4(5,9 ; 6,9)$ & $9,2(7,4 ; 11,5)$ \\
\hline Domestic services & 6.043 .835 & $6,8(6,3 ; 7,3)$ & $10,0(8,2 ; 11,5)$ \\
\hline Other services \# & 593.352 & $0,7(0,5 ; 0,8)$ & $0,7(0,1 ; 4,5)$ \\
\hline
\end{tabular}

\#mining, electricity, gas, and international organizations (C195\%): confidence interval of $95 \%$
Table 3 Crude and adjusted analysis of depression for the variables gender, age, skin color, education level, smoking and region of the country Brazil, 20I3

\begin{tabular}{|c|c|c|c|c|}
\hline Variable & ORb(IC95\%)c & p - value & ORa(IC95\%)c & $p$ - value \\
\hline Sex & & $<0,000 I^{* *}$ & & $<0,000 I^{* *}$ \\
\hline Male & 1 & & 1 & \\
\hline Female & $3,34(2,81 ; 3,98)$ & $<0,00 I^{*}$ & $2,99(2,46 ; 3,63)$ & $<0,00 I^{*}$ \\
\hline Age range & & $<0,0001 * *$ & & \\
\hline$\leq 29$ years & 1 & & I & \\
\hline $30-39$ years & $\mathrm{I}, 79(\mathrm{I}, 40 ; 2,30)$ & $<0,00$ I* & I,7I $(I, 33 ; 2,20)$ & $<0,00 I^{*}$ \\
\hline 40 - 49years & $2,50(1,94 ; 3,23)$ & $<0,00 I^{*}$ & $2,14(1,64 ; 2,78)$ & $<0,00 I^{*}$ \\
\hline $50-59$ years & $2,50(1,92 ; 3,26)$ & $<0,00$ I* & $2,10(1,60 ; 2,76)$ & $<0,00 I^{*}$ \\
\hline$\geq 60$ years & $2,23(1,57 ; 3,17)$ & $<0,00$ I* & $2,09(1,43 ; 3,05)$ & $<0,00 I^{*}$ \\
\hline Skin color & & $<0,000 I^{* *}$ & & \\
\hline No white & 1 & & I & \\
\hline White & I,46 (I,26; I,69) & $<0,00$ I* & I,I2 (0,95; I,33) & $0,174 *$ \\
\hline Educational leve & & $<0,000 I^{* *}$ & & \\
\hline Unread & 1 & & I & \\
\hline $\begin{array}{l}\text { Elementary } \\
\text { school }\end{array}$ & I,63 (I,232; 2,I7) & $=0,00 \mathrm{I} *$ & $\mathrm{I}, 54(\mathrm{I}, \mathrm{I} 4 ; 2,07)$ & $0,004 *$ \\
\hline High school & I, $16(0,88 ; 1,53)$ & $=0,299 *$ & I,25 (0,92; I,70) & $0,154^{*}$ \\
\hline $\begin{array}{l}\text { Higher } \\
\text { education }\end{array}$ & $1,74(1,30 ; 2,32)$ & $<0,00 I^{*}$ & I,5। $(1,06 ; 2,15)$ & $0,023^{*}$ \\
\hline Smoking & & $=0,0004 * *$ & & \\
\hline No & 1 & & 1 & \\
\hline Yes & $1,40(1,16 ; 1,69)$ & $<0,001 *$ & I,47 (I,20; I,80) & $<0,001 *$ \\
\hline Region & & $<0,000 I^{* *}$ & & \\
\hline North & 1 & & 1 & \\
\hline Northeast & I,66 (I,32;2,09) & $<0,00$ I* & I,50 (I,I8; I,9I) & $0,001 *$ \\
\hline Southeast & $2,78(2,21 ; 3,49)$ & $<0,00$ I* & $2,46(1,92 ; 3,15)$ & $<0,00 I^{*}$ \\
\hline South & $4,34(3,44 ; 5,47)$ & $<0,00$ I* & $3,68(2,83 ; 4,79)$ & $<0,00$ I* \\
\hline Midwest & $2,55(2,00 ; 3,25)$ & $<0,00$ I* & $2,31(1,79 ; 2,97)$ & $<0,00 I^{*}$ \\
\hline
\end{tabular}

\section{$\mathrm{OR}^{\mathrm{b}}$ : Crude odds ratio}

$\mathrm{OR}^{\mathrm{a}}$ :Adjusted odds ratio between all the variables IC95\%: Confidence interval of $95 \%$.

**: Maximum likelihood test

*:Wald test 
Table 4 Crude and adjusted depression analysis for the variables sleep deprivation and National Classification of Economic Activities. Brazil, 2013

\begin{tabular}{|c|c|c|c|c|}
\hline Variable & $\mathrm{OR}^{\mathrm{b}}(\mathrm{Cl} 195 \%)^{\mathrm{c}}$ & $p$ - value & $\mathrm{OR}^{\mathrm{a}}(\mathrm{Cl} 195 \%)^{\mathrm{c}}$ & $\mathrm{p}$ - value \\
\hline Sleep deprivation & & $<0,000 I^{* *}$ & & \\
\hline No & 1 & & I & \\
\hline Yes & $3,97(3,42 ; 4,62)$ & $<0,00 I^{*}$ & $3,46(2,97 ; 4,04)$ & $<0,001$ \\
\hline NCEA & & $<0,000 I^{* *}$ & & \\
\hline Transport and storage & 1 & & I & \\
\hline Agriculture, fishing and livestock & $2,05(1,21 ; 3,48)$ & $0,007^{*}$ & $\mathrm{I}, 60(0,92 ; 2,76)$ & $0,094 *$ \\
\hline Transformation industry & $2,47(I, 51 ; 4,09)$ & $<0,00 I^{*}$ & I,65 $(0,92 ; 2,77)$ & $0,060 *$ \\
\hline Sanitation & $3,36(1,23 ; 9,18)$ & $0,018^{*}$ & $2,78(1,02 ; 7,56)$ & $0,045 *$ \\
\hline Construction & $\mathrm{I}, 60(0,87 ; 2,95)$ & $0,133^{*}$ & $\mathrm{I}, 74(0,93 ; 3,26)$ & $0,082^{*}$ \\
\hline Trade and repair & $2,39(1,48 ; 3,87)$ & $<0,001 *$ & I,77 $(1,06 ; 2,94)$ & $0,028^{*}$ \\
\hline Accommodation, food and communication & $2,56(1,50 ; 4,36)$ & $0,001 *$ & I,46 $(0,83 ; 2,57)$ & $0,193 *$ \\
\hline Administrative services & $2,59(1,60 ; 4,22)$ & $<0,001 *$ & I,62 (0,97;2,73) & $0,068^{*}$ \\
\hline Education, arts, culture and sport & $4,20(2,52 ; 6,99)$ & $<0,001 *$ & $\mathrm{I}, 80(1,00 ; 3,25)$ & $0,050 *$ \\
\hline Health and social services & $4,00(2,40 ; 6,69)$ & $<0,00 I^{*}$ & I,83 (I,07; 3, I5) & $0,030 *$ \\
\hline Domestic services & $4,39(2,68 ; 7,17)$ & $<0,00 I^{*}$ & I,6I $(0,94 ; 3,15)$ & $0,085^{*}$ \\
\hline Other services ${ }^{\#}$ & $0,26(0,03 ; ।, 98)$ & $0,195^{*}$ & $0,30(0,04 ; 2,34)$ & $0,253^{*}$ \\
\hline
\end{tabular}

\#mining, electricity, gas, and international organizations

$\mathrm{OR}^{\mathrm{b}}$ : Crude odds ratio

$\mathrm{OR}^{\mathrm{a}}$ :Adjusted odds ratio between all the variables

IC $95 \%$ : Confidence interval of $95 \%$.

**: Maximum likelihood test

*:Wald test

\section{Discussion}

The prevalence of depression among workers in Brazil in 2013 was $6.2 \%$, the outcome was more associated with female gender, age from 40 years, elementary school level, smoking, southern region of the country and insomnia. The prevalence of depressive disorders in economically active populations may vary globally. In surveys conducted in China with workers from private companies, the prevalence of depressive symptoms was $8.1 \%,{ }^{13}$ and among rural workers it was $5.9 \% .{ }^{14}$ In Korea a national survey found $2.7 \%$ of depressive disorders. ${ }^{15}$ In a national survey in Canada, the prevalence of depressive disorders was $9.9 \% .{ }^{16}$ In the United Kingdom analyzing depression from a biobank with 172.751 participants the prevalence of depression was $6.4 \%,{ }^{17}$ corroborating the findings of this study. In surveys conducted in Brazil, the prevalence of depression varied widely, among firefighters in Belo Horizonte, $5.5 \%,{ }^{18}$ and in Sao Paulo, the prevalence of depressive symptoms was $20 \%$ among nursing professionals. ${ }^{19}$

According to a systematic review, prevalence estimates vary substantially from economically more developed countries to less developed ones. These variations between studies can be elucidated by methodological differences, such as the type and representativeness of the population or sampling, validation of the research instrument and statistical accuracy. The distribution of chronic diseases related to human aging and socioeconomic development are other important aspects in the prevalence of depressive disorders. ${ }^{20}$ Studies have associated depression with females, both occupational and in the

general population. ${ }^{15,17,21,22}$ In a study conducted with Chilean workers, the OR of depression was 2.34 , similar to the values found here..$^{22}$ Women exposed to constant work tensions, low rewards and worse working conditions are more likely to develop depressive episodes, which is more common for women. In addition to the reflection of social inequalities and health inequalities. On the other hand, women are more likely to seek health services, which may, to some extent, overestimate the occurrence of the outcome in relation to men. ${ }^{22}$

Despite the fact that women have gained space in the labor market, the difference in the distribution of tasks, positions, and treatment received by both coworkers and superiors still prevails. ${ }^{22}$ Men are often in management and supervisory positions, while women are more likely to perform operational administrative services. Another important aspect to be considered is stressful events such as the daily double shift assumed by women between work and domestic tasks. ${ }^{23}$ Apropos the age group, we observed the highest prevalence of depression among workers over 40 years, that's workers with greater difficulty in entering and maintaining in the labor market. This factor can be attributed to the culture and resistance of the recruitment and human resources sectors to admit older workers, whether due to wage issues, disbelief in innovative knowledge or beliefs of work disability at older ages. ${ }^{24}$ For skin color, some research has found an association between depression and white workers. However, the racial/ethnic issue alone does not justify this association, this aspect is possibly more related to unfavorable working conditions, chronic health problems, racial, cultural and religious factors that may interfere with and contribute to self-reported emotions. Association. ${ }^{25-27}$ 
About education level as a factor associated with depression, the literature presents divergent results with positive associations or without confirmed associations. ${ }^{16,28-30}$ This divergence can be attributed to the sample size, ethnic differences and economic development of the country where the study is developed. ${ }^{28}$ However, it is pertinent to highlight that the level of education is a determining factor for the maintenance and structuring of employment/occupation and economy, and is associated with social class. ${ }^{28,29,31}$ The worker with low education level tends to perform manual work, with lower pay, which can cause economic insecurity. In addition, there is a threat to job retention due to high competition for jobs in these less demanding occupations. On the other hand, workers with the highest level of education tend to occupy management positions, with better salaries, more autonomy, but with higher intellectual demands. ${ }^{28,30,32}$ Regarding lifestyle variables, smoking and sleep deprivation obtained the highest prevalence of depression in relation to their references. According to a Dutch study, depressive symptoms are more severe in smokers, especially when there is nicotine dependence. ${ }^{33}$ Similarly, tobacco use is generally higher in people with depression in the general population. ${ }^{17}$ This relationship of dependence occurs because nicotine is a psychoactive substance that acts under neural activity providing mood boost, so that individuals smoke both for the false sense of pleasure and to relieve depressive symptoms ${ }^{34}$ Appurtenant sleep deprivation, in addition to the significant prevalence rate, this was an important variable for adjusting the level of stress regarding gender, especially among females. According to the literature, depression is associated with both short and long periods of sleep. In addition, to revealing different gender patterns with higher rates of suicidal thoughts among men and stress and depressive symptoms among women, disorders directly influenced by female hormones. ${ }^{35-37}$

Regarding the regions of the country, there was a highlight especially for the South and Southeast where there was a greater association with depression. One of the possibilities to elucidate this fact is the hypothesis of climatic seasonality. Because these are cooler places, compared to other regions, there may be differences in depression between seasons. ${ }^{38}$ In addition, the fact that Brazil is a country with continental dimensions should also consider the level of socioeconomic development, differences in access to health services, the distribution of diseases, which may differ from region to region, as well as structuring of the work process and predominant economic activity.Concerning economic activity, the greatest association with depression was evidenced in trade and repair, health and social services and sanitation activities. A study conducted in Singapore's general employed population found the highest prevalence of depression among service and sales professionals (7.7\%), legislators $(6.9 \%)$ and professional employees and managers $(6.9 \%){ }^{39}$

It is noteworthy that less qualified professionals working in physically demanding activities are more likely to have physical exhaustion, emotional exhaustion and depressive symptoms than other workers. ${ }^{32,40}$ In health workers, there are several factors attributed to mental illness. Long daily and weekly working hours, and oncall work, including night work. The shortage of professionals, the consequent request for overtime, work overload and low pay are some of the conditions that may influence this fact. ${ }^{41}$ In addition to these situations, specific characteristics of health care scenarios increase the negative effects on workers' performance and health. Developing countries, issues related to institutions such as organization of time, work, scarcity of material resources, budget constraints, inadequate facilities and poor administrative arrangements result in high levels of fatigue and stress among workers. ${ }^{41}$ There were limitations in this study, such as reverse causality between outcome and exposure variables, as it is a cross-sectional view. In addition, the outcome in question may have been underestimated, as access to treatment as well as proper diagnosis may not be accessible to all.Study participants answered several questions about depression broadly, not specifically, in addition to general health and other aspects. However, the alternation of topics may have aided the "blind" effect in relation to the study hypotheses between interviewees and interviewers. Ensuring anonymity may have reduced information bias. The sample was representative of the economically active population of Brazil, which makes it possible to draw profiles, generate hypotheses, and to estimate prevalence in a comprehensive manner and associated factors.

\section{Conclusion}

This study found an intermediate prevalence of depression among workers in Brazil (6.2\%) and lower than in the general population, and compared to the literature. Female gender, age over 40 years, smoking, living in the southern region of the country, and suffering from sleep deprivation were the factors most associated with the outcome in the multiple model. Prospective studies, such as cohort studies with a representative sample, are recommended to better elucidate the associations found in this study. Even perform causal inference analysis on other more specific aspects in relation to work and grievance-specific activities.

\section{Declaration}

The authors contributed equally for this research work.

\section{Financial support}

None.

\section{Conflicts of interest}

Author declares that there is no conflict of interest.

\section{References}

1. Castellón Leal E, Regàs PI, Planas MG, et al. El abordaje de la depresiónen el ámbito del trabajo: recomendaciones clave. Psiq Biol. 2016; 23(3):112-117.

2. Andreeva E, Hanson LLM, Westerlund H, et al. Depressive symptoms as a cause and effect of job loss in men and women: evidence in the context of organisational downsizing from the Swedish Longitudinal Occupational Survey of Health. BMC Public Health. 2015;15:1045.

3. Ferrari AJ, Charlson FJ, Norman RE, et al. The Epidemiological Modelling of Major Depressive Disorder: Application for the Global Burden of Disease Study 2010. PLoS One. 2013; 8(7):e69637.

4. Santana LL, Miranda FMA, Karino MEK, et al. Description of workloads and fatigue experienced among health workers in a teaching hospital. Rev Gaúcha Enferm. 2013; 34(1):64-70.

5. Mckenzie DP, Sima MR, Clarke DM, et al. Developing a brief depression screen and identifying associations with comorbid physical and psychological illness in Australian Gulf War veterans. J Psychosom Res. 2015;79(6):566-573.

6. Muntaner C, Edwin Ng, Prins SJ, et al. Social Class and Mental Health: Testing Exploitation as a Relational Determinant of Depression. Int $J$ Health Serv. 2015;45(2): 265-284.

7. Kim WK, Shin D, Song WO. Depression and Its Comorbid Conditions More Serious in Women than in Men in the United States. $J$ Womens Health (Larchmt). 2015;24(12):978-85. 
8. Waters RP, Rivalan M, Bangasser DA, et al. Evidence for the role of corticotropin-releasing factor in major depressive disorders. Neurosci Biobehav Rev. 2015; 58:63-78.

9. World Health Organization. Depression and Other Common Mental Disorders Global Health Estimates. WHO, Geneva, Switzerland, 2017. p. 24.

10. Niedhammer I, Chastang JF. Psychosocial work factors and first depressive episode: retrospective results from the French national SIP survey. Int Arch Occup Environ Health. 2015; 88(7):835-847.

11. Brasil. Instituto Brasileiro de Geografia e Estatística (IBGE). Banco de dados agregados: Pesquisa nacional por amostra de domicílios (PNAD): pesquisa básica. 2013.

12. Brasil. Ministério do Planejamento, orçamento e Gestão. Instituto Brasileiro de Geografia e estatística - IBGE. Pesquisa Nacional de Saúde 2013. Percepção do estado de saúde, estilos de vida e doenças crônicas. Brasil, grandes regiões e Unidades da Federação. IBGE: Rio de Janeiro, 2014.

13. Sun J, Buys N, Wang X. Depression in Employees in Privately Owned Enterprises in China: Is It Related to Work Environment and Work Ability? Int J Environ Res Public Health. 2013; 10(4):1152-1167.

14. Zhou X, Bi B, Zheng L, et al. The Prevalence and Risk Factors for Depression Symptoms in a Rural Chinese Sample Population. PLoS One. 2014;9(6): e99692.

15. Kim JH, Cho MJ, Hong JP, et al. Gender Differences in Depressive Symptom Profile: Results from Nationwide General Population Surveys in Korea. Korean Med Sci. 2015; 30(11): 1659-1666.

16. Patten SB, Williams JVA, Lavorato DH, et al. Descriptive Epidemiology of Major Depressive Disorder in Canada in 2012. Can J Psychiatry. 2015; 60(1):23-30

17. Smith DJ, Nicholl BI, Cullen B, et al. Prevalence and Characteristics of Probable Major Depression and Bipolar Disorder within UK Biobank: Cross-Sectional Study of 172,751 Participants. PLoS One. 2013; 8(11) e75362.

18. Lima EP, Assunção AA, Barreto SM. Prevalência de depressão em bombeiros. Cad Saúde Pública. 2015; 31:733-743.

19. Gherardi-Donato ECS, Cardoso L, Teixeira CAB, et al. Associação entre depressão e estresse laboral em profissionais de enfermagem de nível médio. Rev Latino-Am Enfermagem. 2015;23(4):733-740.

20. Kessler RC, Bromet EJ. The epidemiology of depression across cultures Annu Rev Public Health. 2013;34:119-138.

21. Cunha RV, Bastos GAN, Del Duca GF. Prevalência de depressão e fatores associados em comunidade de baixa renda de Porto Alegre, Rio Grande do Sul. Rev Bras Epidemiol. 2012;15(2):346-354.

22. Ansoleaga E, Vézina M, Montaño R. Síntomas depresivos y distrés laboral en trabajadores chilenos: condiciones diferenciales para hombres y mujeres. Cad Saúde Pública. 2014; 30(1):107-118.

23. Niedhammer I, Malard L, Chastang J. Occupational factors and subsequent major depressive and generalized anxiety disorders in the prospective French national SIP study. BMC Public Health. 2015; 15:200.

24. Sun J, Buys N, Wang X. Depression in Employees in Privately Owned Enterprises in China: Is It Related to Work Environment and Work Ability? Int J Environ Res Public Health. 2013;10(4):1152-1167.

25. Stopa SR, Malta DC, Oliveira MM, et al. Prevalência do autorrelato de depressão no Brasil: resultados da Pesquisa Nacional de Saúde, 2013. Rev Bras Epidemiol. 2015;18(Supple 2):170-180.
26. Nieuwenhuijsen K, Schene AH, Stronks K, et al. Do unfavourable working conditions explain mental health inequalities between ethnic groups?: cross-sectional data of the HELIUS study. BMC Public Health. 2015;15:805

27. Chentsova-Dutton YE, Choi E, Ryder AG, Reyes J. "I felt sad and did not enjoy life": Cultural context and the associations between anhedonia, depressed mood, and momentary emotions. Transcult Psychiatry. 2015; 52(5): 616-635.

28. Prins SJ, Bates LM, Keyes KM, et al. Anxious? Depressed? You might be suffering from capitalism: contradictory class locations and the prevalence of depression and anxiety in the USA. Sociology of Health \& Illness. 2015; 37(8):1352-1372.

29. Kim J, Lee SG, Shin S, et al. Impact of the gap between socioeconomic stratum and subjective social class on depressive symptoms: Unique insights from a longitudinal analysis. Soc Sci Med. 2014;120:49-56.

30. Kosidou K, Dalman C, Lundberg M, et al. Socioeconomic status and risk of psychological distress and depression in the Stockholm Public Health Cohort: A population-based study. J Affect Disord. 2011;134(1-3):160 167.

31. Miyaki K, Song Y, Taneichi S, et al. Socioeconomic Status Is Significantly Associated with the Dietary Intakes of Folate and Depression Scales in Japanese Workers (J-HOPE Study). Nutrients. 2013;5(2):565-578.

32. Torske MO, Hilt B, Bjørngaard JH, et al. Disability pension and symptoms of anxiety and depression: a prospective comparison of farmers and other occupational groups. BMJ Open. 2015;5(11):e009114.

33. Jamal M, Van der Does AJW, Cuijpers P, et al. Association of smoking and nicotine dependence with severity and course of symptoms in patients with depressive or anxiety disorders. Drug Alcohol Depend. 2012;126(1-2):138-146.

34. Cheng HG, Chen S, Mcbride O, et al. Prospective relationship of depressive symptoms, drinking, and tobacco smoking among middleaged and elderly community-dwelling adults: Results from the China Health and Retirement Longitudinal Study (CHARLS). J Affect Disord. 2016;195:136-143

35. Lee M, Shin JS, Lee J, et al. The association between mental health, chronic disease and sleep duration in Koreans: a cross-sectional study. BMC Public Health. 2015;15:1200.

36. Lima MG, Bergamo FPM, Barros MBA. Sleep duration pattern and chronic diseases in Brazilian adults (ISACAMP, 2008/09). Sleep Med. 2012;13(2):139-144.

37. Martín-Merino E, Pharm B, Ruigómez A, et al. Study of a cohort of patients newly diagnosed with depression in general practice. Prevalence, incidence, comorbidity, and treatment patterns. Prim Care Companion J Clin Psychiatry. 2010; 12(1): PCC.08m00764.

38. Disanto G, Morahan JM, Lacey MV, et al. Seasonal Distribution of Psychiatric Births in England. PLoS One. 2012;7(4):e34866.

39. Vaingankar JA, Subramaniam M, Chong SA, et al. Prevalence of Chronic Mental and Physical Disorders, Impact on Work Productivity and Correlates of Alcohol Use Disorders and Nicotine Dependence across Occupations. Ann Acad Med Singapore. 2015; 44(4):133-144.

40. Marchand A, Blanc ME, Durand P. Genre, âge, catégorieprofessionnelle, secteuréconomique et santé mentaleen milieu de travail: les résultats de l'étude SALVEO. Can J Public Health. 2015;106(4):e223-e229.

41. Messenger JC, Vidal P. The organization of working time and its effects in the health services sector: A comparative analysis of Brazil, South Africa and the Republic of Korea. In: International Labour Office. Geneva, 2015. p. $1-72$. 